ИЗВЕСТИЯ АКАДЕМИИ НАУК ЭСТОНСКОН ССР. ТОМ 30 Химия. 1981, № 1

А. ШЕВЧЕНКО, Айли КОГЕРМАН, Марет КРУЛЛЬ, Э. ХЕИНСОО, С. БОКОВА, О. КНРРЕТ

\title{
ИССЛЕДОВАНИЕ ПИРОЛИЗА ВИСКОЗНЫХ ВОЛОКОН МЕТОДОМ ПИРОЛИТИЧЕСКОЙ ГАЗОВОЙ ХРОМАТОГРАФИИ
}

Известно, что тонкая физическая структура целлюлозы влияет на скорость и направление процессов пиролиза [1-3]. Для изучения процессов, сопутствующих пиролизу полимерных материалов, в том числе и целлюлозы, широко используются физико-химические (ИК-спектроскопия, ДСК, ТГА, рентгеноскопия, ЭПР, хроматография), а также химические методы.

В данной работе приводятся результаты исследования влияния тонкой структуры на пиролиз различных вискозных волокон с помощью методов пиролитической газовой хроматографии (ПГХ) и ступенчатой пиролитической газовой хроматографии (СПГХ). Эти методы позволяют получить более обширную информацию о продуктах термического распада, чем другие физико-химические методы, оценить состав и содержание продуктов деструкции полимера при кратковременном нагревании материала [ $\left.{ }^{4}\right]$. Қак было показано ранее, данные СПГХ хорошо согласуются с данными ТГА и ДТА [5].

Объектами исследования служили: вискозная текстильная нить $(\mathrm{BTH})$, вискозная кордная нить (ВКН) и вискозное штапельное волокно (ВШВ). Использовались образцы, очищенные от примесей и отделочных препаратов, характеристика их представлена в табл. 1.

Между вискозными волокнами текстильного назначения и кордной нитью существует структурно-морфологическое различие. Поперечный срез у вискозной текстильной нити и штапельного волокна неоднороден и состоит из оболочки (внешний слой) и ядра (внутренний слой), отличающихся по структуре и свойствам. Вискозная кордная нить более однородна, на ее поперечном срезе не обнаружена разница между внутренним и внешним слоями. Для высокопрочного вискозного корда характерны мелкокристаллические надмолекулярные образования и относительно высокая степень ориентации элементов структуры вдоль оси волокна [6].

Таблица 1

Характеристика образцов вискозных волокон

\begin{tabular}{|c|c|c|c|c|c|c|c|}
\hline $\begin{array}{c}\text { Во- } \\
\text { локно }\end{array}$ & $\begin{array}{l}\text { Прочность, } \\
\text { ес/текс }\end{array}$ & $\begin{array}{c}\text { Удлинение, } \\
\%\end{array}$ & $\begin{array}{c}\text { Ст. крис- } \\
\text { таллич- } \\
\text { ности, \% }\end{array}$ & $\mathrm{C \Pi}$ & $\begin{array}{l}\text { Фактор } \\
\text { ориен- } \\
\text { тации }\end{array}$ & $\begin{array}{c}\text { Содер- } \\
\text { жание } \\
\text { золы, } \\
\%\end{array}$ & $\begin{array}{l}\text { Раство- } \\
\text { римость } \\
\text { B 5\%-ном } \\
\mathrm{NaOH}, \%\end{array}$ \\
\hline $\begin{array}{l}\text { BKH } \\
\text { BTH } \\
\text { ВШB }\end{array}$ & $\begin{array}{r}39-40 \\
16,1-16,2 \\
20-20,6\end{array}$ & $\begin{array}{r}11-12 \\
13,8-13,9 \\
26-27,5\end{array}$ & $\begin{array}{c}40 \\
39 \\
37-39\end{array}$ & $\begin{array}{l}400 \\
300 \\
280\end{array}$ & $\begin{array}{c}0,42-0,5 \\
0,31 \\
0,31\end{array}$ & $\begin{array}{l}0,35 \\
0,41 \\
0,43\end{array}$ & $\begin{array}{l}4,4 \\
2,3 \\
2,0\end{array}$ \\
\hline
\end{tabular}

2 ENSV TA Toimetised. K 11981 

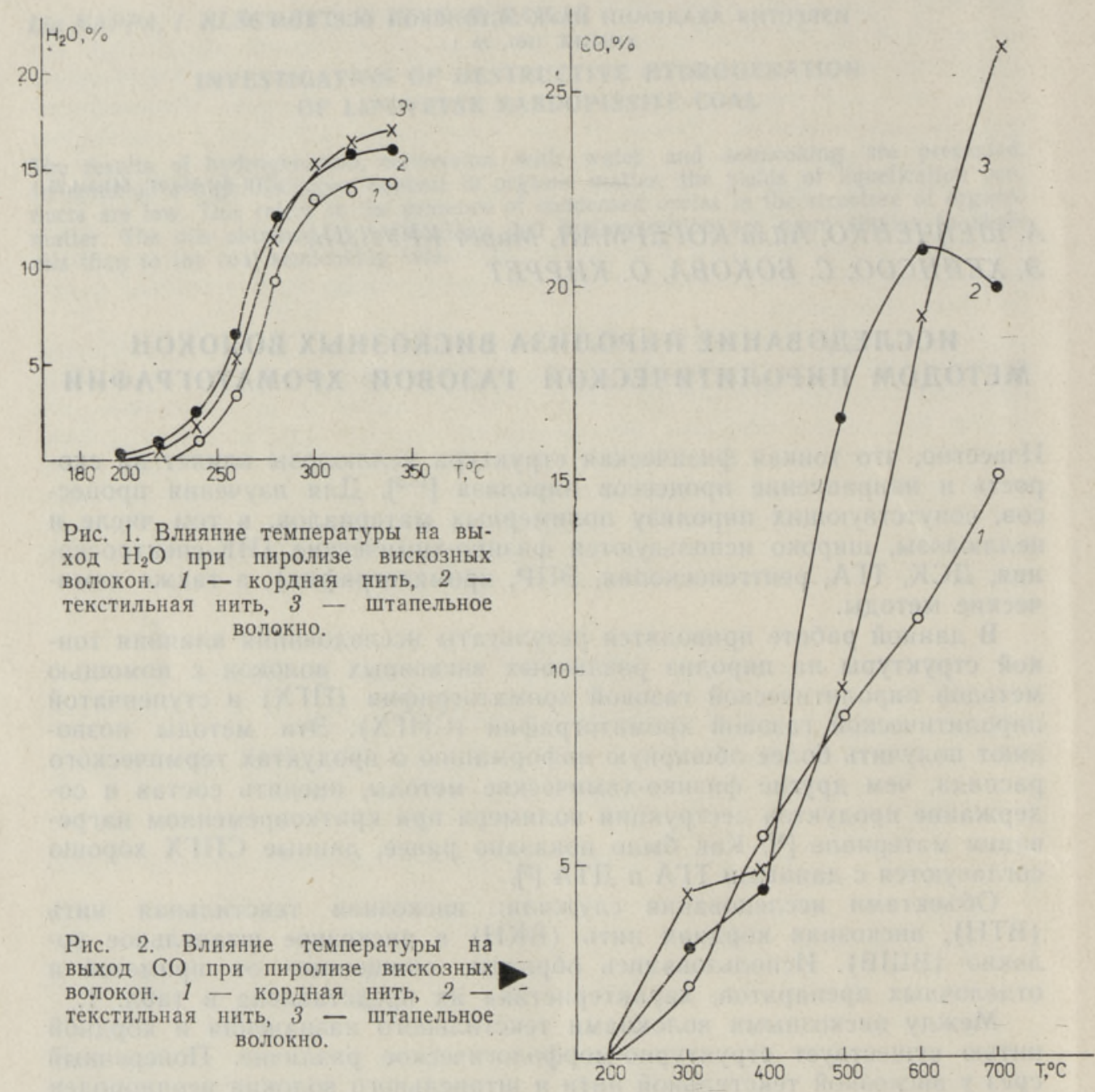

Рис. 1. Влияние температуры на выход $\mathrm{H}_{2} \mathrm{O}$ при пиролизе вискозных волокон. 1 - кордная нить, 2 текстильная нить, 3 - штапельное волокно.

Рис. 2. Влияние температуры на выход СО при пиролизе вискозных волокон. 1 - кордная нить, 2 текстильная нить, 3 - штапельное волокно.

Выбранные объекты различаются по СП и растворимости в $5 \%$-ном растворе $\mathrm{NaOH}$, которая характеризует доступность структуры. Пиролиз образцов проведен в пиролизаторе, нагреваемой платиновой спиралью, в области температур $100-700^{\circ} \mathrm{C}$ по двум схемам. В первом случае образцы $(\sim 1$ мг) нагревали при определенных температурах $\left(200-700^{\circ}\right)$ в течение 15 сек, затем определяли количественный состав летучих продуктов пиролиза. Более подробно изучался пиролиз методом СПГХ в области температур $100-350^{\circ}$, для этого образец весом 5-10 ме нагревали в пиролизаторе, поднимая температуру пиролиза ступенчато через каждые $10-20^{\circ}$. Длительность каждого нагрева 15 сек. По окончании нагрева определяли количественный выход $\mathrm{H}_{2} \mathrm{O}$, $\mathrm{CO}$ и $\mathrm{CO}_{2}$.

Наличие большого числа ОН-групп, их взаимное расположение с другими атомами в элементарном звене и относительно невысокая стабильность к тепловому воздействию приводят к дегидратации целлюлозы в процессе пиролиза. Эта реакция имеет большое значение, так как определяет состав продуктов распада и выход углерода. По количеству выделившейся воды при пиролизе исследуемых образцов вис- 


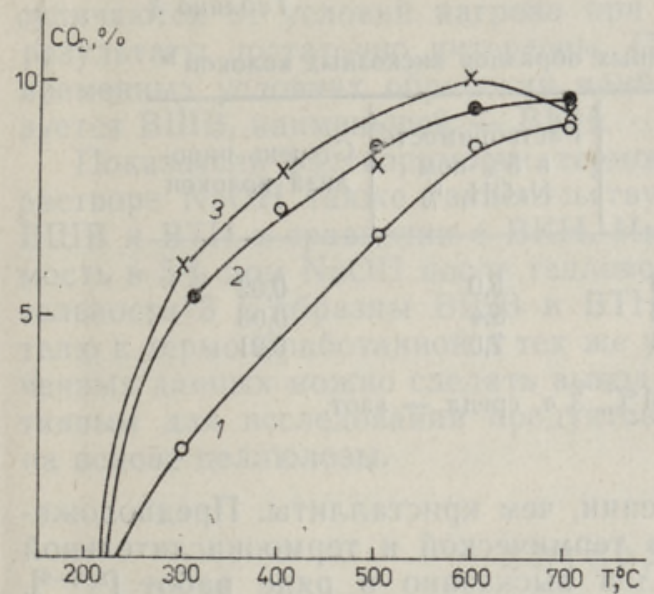

Рис. 3. Влияние температуры на выход $\mathrm{CO}_{2}$ при пиролизе вискозных волокон. 1 кордная нить, 2 - текстильная нить, 3 штапельное волокно.

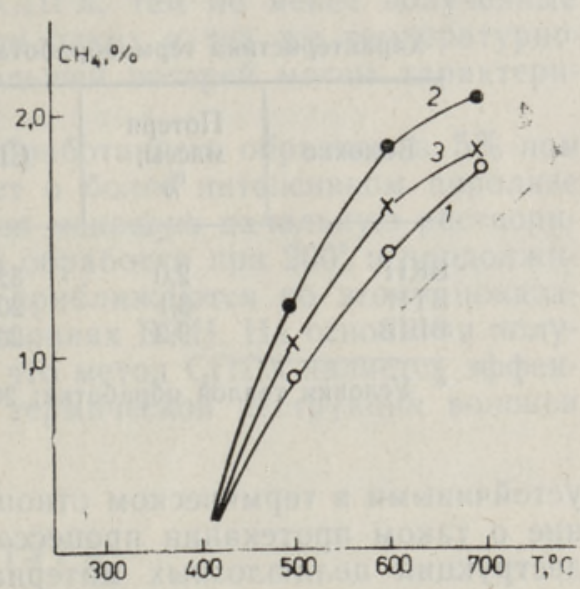

Рис. 4. Влияние температуры на выход $\mathrm{CH}_{4}$ при пиролизе вискозных волокон. 1 - кордная нить, 2 - текстильная нить, 3 - штапельное волокно.

Таблица 2

Выход летучих продуктов разложения, образующихся при пиролизе вискозных волокон, \%

\begin{tabular}{|c|c|c|c|c|c|c|}
\hline \multirow{2}{*}{ Волокно } & \multirow{2}{*}{$\begin{array}{c}\text { Продукты } \\
\text { разложения }\end{array}$} & \multicolumn{5}{|c|}{ Температура, ${ }^{\circ} \mathrm{C}$} \\
\hline & & 300 & 400 & 500 & 600 & 700 \\
\hline \multirow[t]{2}{*}{ BTH } & $\begin{array}{l}\mathrm{CO} \\
\mathrm{CO}_{2} \\
\mathrm{CH}_{4} \\
\text { Oбщеe }\end{array}$ & $\begin{array}{l}3,85 \\
5,6 \\
-\end{array}$ & $\begin{array}{l}4,25 \\
6,6 \\
\text { следы }\end{array}$ & $\begin{array}{r}16,5 \\
8,8 \\
1,2\end{array}$ & $\begin{array}{c}21,0 \\
9,5 \\
1,86\end{array}$ & $\begin{array}{r}20,0 \\
9,7 \\
2,1\end{array}$ \\
\hline & кол-во & 9,45 & 10,85 & 26,5 & 32,36 & 31,8 \\
\hline \multirow[t]{2}{*}{ BKH } & $\begin{array}{l}\mathrm{CO} \\
\mathrm{CO}_{2} \\
\mathrm{CH}_{4} \\
\text { Oбщеe }\end{array}$ & $\begin{array}{l}1,9 \\
2,15 \\
-\end{array}$ & $\begin{array}{l}5,75 \\
7,3 \\
-\end{array}$ & $\begin{array}{l}8,8 \\
6,7 \\
0,69\end{array}$ & $\begin{array}{c}11,35 \\
8,9 \\
1,4\end{array}$ & $\begin{array}{c}15,0 \\
9,2 \\
1,76\end{array}$ \\
\hline & кол-во & 4,05 & 13,05 & 16,19 & 21,65 & 25,96 \\
\hline \multirow[t]{2}{*}{ ВШВ } & $\begin{array}{l}\mathrm{CO} \\
\mathrm{CO}_{2} \\
\mathrm{CH}_{4} \\
\text { Общее }\end{array}$ & $\begin{array}{l}4,3 \\
6,1 \\
-\end{array}$ & $\begin{array}{c}4,8 \\
8,0 \\
\text { следы }\end{array}$ & $\begin{array}{l}9,6 \\
8,35 \\
0,83\end{array}$ & $\begin{array}{c}19,4 \\
10,25 \\
1,6\end{array}$ & $\begin{array}{r}26,8 \\
9,3 \\
1,8\end{array}$ \\
\hline & кол-во & 10,4 & 12,8 & 18,78 & 31,25 & 37,9 \\
\hline
\end{tabular}

козных волокон методом СПГХ можно судить об интенсивности дегидратации в зависимюсти от их тонкой физической структуры (рис. 1). Из рис. 1 видно, что при пиролизе вискозной нити и вискозного штапельного волокна количество образовавшейся воды больше, чем при пиролизе вискозной кордной нити. Это свидетельствует о более интенсивной дегидратации этих видов вискозных волокон. При этом процесс дегидратации у вискозных волокон текстильного назначения начинается при более низких температурах (на 25-30²), чем у ВКН.

Процесс пиролиза волокон является гетерогенным: начинается в межкристаллитных аморфных участках, а затем захватывает кристаллические области. Таким образом, аморфные участки являются менее 
Таблица 3

Характеристика термообработанных образцов вискозных волокон *

\begin{tabular}{l|c|c|c|c}
\hline Волокно & $\begin{array}{c}\text { Потеря } \\
\text { массы, } \\
\%\end{array}$ & СП & $\begin{array}{c}\text { Растворимость } \\
\text { в 5\%-ном } \\
\text { NaOH, \% }\end{array}$ & $\begin{array}{c}\text { Степень пиро- } \\
\text { лиза волокон }\end{array}$ \\
\hline BКH & 2,0 & 320 & 5,0 & 0,02 \\
BTH & 3,1 & 202 & 5,4 & 0,03 \\
ВШВ & 9,2 & 206 & 7,0 & 0,91
\end{tabular}

* Условия теплой обработки: $200^{\circ} \mathrm{C}, 3$ и, среда - азот.

устойчивыми в термическом отношении, чем кристаллиты. Предположение о таком протекании процессов термической и термоокислительной деструкций целлюлозных материалов высказано в ряде работ [3,6-9], подсчитаны энергии активации []. Если исходить из того, что пиролиз целлюлозы происходит вначале в менее упорядоченных участках, то становится понятной ускоренная дегидратация менее ориентированных структурно неоднородных ВТН и ВШВ.

Одновременно с дегидратацией протекает и деполимеризация, вызывающая потерю массы в результате выделения летучих газообразных продуктов распада целлюлозы и снижение ее СП.

В табл. 2 и на рис. 2-4 представлены данные по выделению СО, $\mathrm{CO}_{2}$ и $\mathrm{CH}_{4}$ при пиролизе исследуемых вискозных волокон.

Из приведенных данных видно, что в исследуемых диапазонах температур и условиях нагрева деструкция ВТН и ВШВ протекает интенсивнее, чем деструкция ВКН. По-видимому, как и в случае дегидратации, деструкция с выделением летучих продуктов начинается в аморфных участках и применительно к структурно неоднородным по поперечному срезу ВТН и ВШВ это выражается в более интенсивном выделении $\mathrm{CO}, \mathrm{CO}_{2}, \mathrm{CH}_{4}$ при более низких температурах.

Сочетание метода ПГХ с другими методами оценки термической деструкции исследуемых образцов вискозных волокон позволило дополнить сведения о влиянии надмолекулярной структуры волокон на ин-

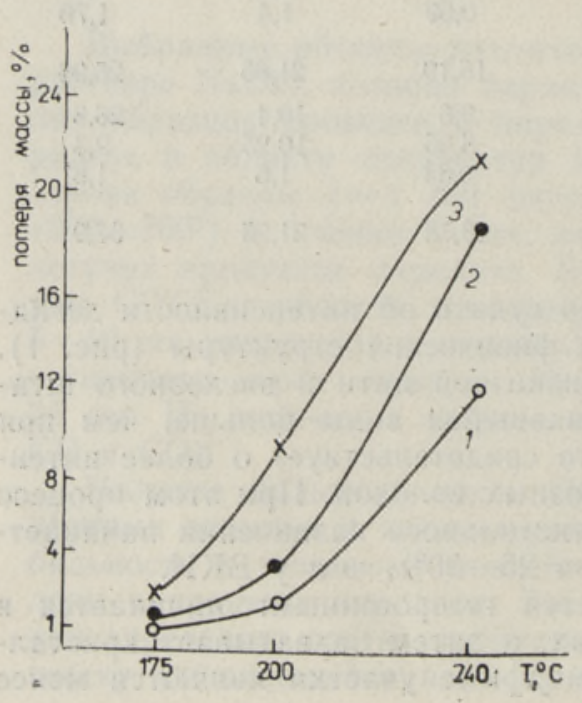

тенсивность пиролиза. Подтверждением более интенсивного пиролиза ВТН и ВШВ в сравнении с ВКН являются данные о потере массы и снижении СП целлюлозы в термообработанных образцах. На рис. 5 и в табл. 3 представлены данные o потере массы и снижении СП в условиях изотермического нагрева в диапазоне температур 175-240 в среде азота в течение $1-3$ и. Хотя условия нагрева в данном случае

Рис. 5. Влияние температуры обработки в азоте на потерю массы вискозных волокон (продолжительность 3 ч). 1 кордная нить, 2 - текстильная: нить, 3 - штапельное волокно. 
отличаются от условий нагрева при СПГХ, тем не менее нолученные результаты достаточно интересны. При одних и тех же температурновременных условиях обработки наибольшей потерей массы характеризуется ВШВ, наименьшей - ВКН.

Показатель растворимости термообработанных образцов в $5 \%$-ном растворе $\mathrm{NaOH}$ также свидетельствует о более интенсивном пиролизе ВШВ и ВТН в сравнении с ВКН. Имея меньшую начальную растворимость в $5 \%$-ном $\mathrm{NaOH}$ после тепловой обработки при $200^{\circ}$ и продолжительности 3 и образцы ВШВ и ВТН приближаются по этому показателю к термообработанной в тех же условиях ВКН. На основании полученных данных можно сделать вывод, что метод СПГХ является эффективным для исследования продуктов термической деструкции волокон на основе целлюлозы.

\section{Л ИТ Е Р А Т У А}

1. Ж банков Р. Г., Конкин А. А., Бы чков а Т. С. Влияние структуры целлюлозных волокон на процесс их термической деструкции. - Хим. вол., 1976, № 1 , c. 31 .

Ж банков Р. Г., Конкин А. А., Бычков а Т. С. Применение метода инфракрасной спектроскопии для исследования структурных и химических превращений природной целлюлозы в процессе термического воздействия. - Хим. вол., 1976, № 4 , с. 54 .

2. Фи алков А. С., Кучин и кая О. Ф. Влияние структуры вискозного волокна на особенности его пиролиза. - Химия тв. топлива, 1968, № 3, c. $116-122$.

3. B a sch, A., Levin, M. The influence of the thin structure on the pyrolysis of cellulose. - J. Polymer Sci., Polymer Chem. Ed., 1973, v. 11, p. 3071-3093.

4. Kru11, M., Kogerman, A., Kirret, O., Kutyina, L., Z a polski, D. Pyrolysis gas-chromatography of capron (nylon-6) fibre stabilised with ethers of 4-oxydiphenylamine. - J. Chrom., 1977, v. 135, p. 212-216.

5. Heinsoo, E., Kogerman, A., Kirret, O., Coupek, J., Vilkova, S. Steplike pyrolysis gas chromatography of viscose fibres. - JAAP, 1980, c. 131-139.

6. Конкин А. А., Кудряв цев Г. И., Серков А. Т. Производство шинного корда. М., 1964, с. 214.

7. Слуцкер Л. И., Утевский Л. Е., Черейский 3 . Ю., Волохина А. В., Перепелкин К. Е. Большие периоды в волокнах из полностью ароматизированных полимеров. (Препринт.) Международный Симпозиум по хим. волокнам. Калинин, 1977, I, с. 125.

8. Громов Б. А., Зубов Ю. А., Кирюшкин С. Г., Марвин А. П., Рап попорт Н. Я., Селехов В. И., Шляпников Ю. А. Диффузионное окисление ориентированного полипропилена. - ВМС, сер. Б, 1973, т. 15, № 8, c. 580 .

9. Добровольская И. П., Утевский Л. Е., Черейский 3. Ю. Об энергии активации процесса пиролиза межкристаллитных аморфных участков гидратцеллюлозных волокон. - ВМС, сер. А, 1978, т. 20, № 11, с. 2538.

\footnotetext{
Институт химии

Академии наук Эстонской ССР
}

Поступила в редакцию 17/III 1980 
A. SEVTSENKO, Aili KOGERMAN, Maret KRULL,

E. HEINSOO, S. BOKOVA, O. KIRRET

\section{VISKOOSKIU POROLOUSGAASIKROMATOGRAAFILINE UURIMINE}

Artiklis on toodud andmeid pürolüüsgaasikromatograafia kasutamisest hüdraattsellulooskiu füüsikalise struktuuri uurimisel. On näidatud, et dehüdratatsiooni ja destruktsiooni kiirus sõltub kiu füüsikalisest struktuurist ja termodestruktsioon algab kiu amorfsetes osades.

A. SHEVCHENKO, Aili KOGERMAN, Maret KRULL,

E. HEINSOO, S. BOKOVA, O. KIRRET

\section{INVESTIGATION OF VISCOSE FIBRES BY PYROLYSIS GAS CHROMATOGRAPHY}

In this work data are presented on the application of pyrolysis gas chromatography in investigating the physical structure of regenerated cellulose fibre. It is demonstrated that the dehydration rates and destruction reactions depend upon the physical structure of the fibre, and that thermal destruction begins in the amorphous part of the fibre. 